\title{
Protected Values and Omission Bias
}

\author{
Ilana Ritov \\ Hebrew University of J erusalem, Israel \\ and \\ J onathan Baron \\ University of Pennsylvania
}

\begin{abstract}
Protected values (PVs) are those that people think should not be traded off. Baron and Spranca (1997) proposed that such values result from rules concerning actions (as opposed to values for outcomes). This proposal implies that PVs should show a particularly large bias against harmful acts that undermine the value in question, as opposed to harmful omissions (omission bias). We found this correlation between PVs and omission bias in 3 experiments, using stimuli of the sort that we used before to demonstrate omission bias. In 2 experiments, we also found a weak tendency for PVs to be associated with lack of concern for the number of acts involved, which is analogous to earlier results showing an association with lack of concern for the quantity of outcomes. Finally, 1 experiment showed that some people are willing to sacrifice values to prevent losses more than they are willing to sacrifice these values for gains. 1999 Academic Press
\end{abstract}

\section{INTRODUCTION}

M ost people have some values that they think of as absolute, not to be traded off for anything else. These includevalues for the natural environment, human or animal life, human rights, sacred objects, and works of art and other human creations. These values create problems for cost-effectiveness analysis based on judgments of value. If these values are accepted, they trump all other values and dictate the decision. If one person places an infinite value on the protection

This research was supported by NSF Grant SBR95-20288.

Address correspondence and reprint requests to J onathan Baron, Department of Psychology, University of Pennsylvania, 3815 Walnut Street, Philadelphia, PA 19104-6196. E-mail: baron@ psych.upenn.edu. 
of species, a government policy that respects all people's values will do everything possible to prevent extinctions.

Baron and Spranca (1997) called these protected values (PVs) and proposed a theory of their nature. They proposed that the values arise from deontological rules, rules concerning actions rather than consequences. By this account, what is absolute is the prohibition against acts that would destroy species of animals or violate human rights. If this theory is correct, then it may be possible to respect these values without also doing everything possible to prevent the bad outcomes in question (e.g., extinctions).

This proposal implies that PVs have several properties, and Baron and Spranca found evidence for most of these properties. First, PVs concern actions but not omissions. Failure to prevent an outcome such as the disappearance of a species may be bad, but the prohibition against such omissions is not absolute. If it were, people who held such values would be obliged to spend their lives looking for ways to promote them. This property is central to the theory, but Baron and Spranca did not test it. The main purpose of the present article is to test this prediction.

Second, because PVs concern acts but not outcomes, they should be insensitive to the quantity of the outcome. Baron and Spranca found support for this insensitivity to quantity of the outcome (and so did Lim \& Baron, 1997). Of course, people who hold PVs may also value outcomes as well as actions, so we would not expect such people to be completely insensitive to quantity of the outcome, and they were not completely insensitive. Still, even a small effect is theoretically important.

The third central property of PVs is agent relativity: the participation of the actor is crucial even when the consequences are the same. For example, people are more likely to think it is morally wrong to buy stock in a company that violates a PV (e.g., by exploiting workers) even when the purchase will have no effect on the share price or the company's behavior. We are not concerned with this property here. Baron and Spranca al so suggested other, more derived properties of PVs, such as their association with emotion, which also do not concern us here.

The main hypothesis of interest is that PVs will show stronger omission bias than will other values. Omission bias is the tendency to be less concerned with harms caused by omission than with identical harms caused by action. In a typical demonstration of this phenomenon, subjects read a scenario in which the same kind of harmful consequences could result from action or omission, but the omission leads to more of it. For example, an epidemic would cause 10 out of 10,000 children to die, and a vaccine that would prevent these deaths would also cause 5 out of 10,000 children to die. Many subjects oppose such a vaccine both for their own child and as a matter of policy (Ritov \& Baron, 1990; similar results have been found by Asch et al., 1994; Baron, 1992; Baron \& Ritov, 1994; Cohen \& Pauker, 1994; Meszaros et al., 1996; Petrinovich \& O’Neill, 1996; Ritov \& Baron, 1992, 1995; and Spranca Minsk, \& Baron 1991).

Most studies of omission bias ask subjects for a threshold amount of harm from action. The threshold is the highest amount of harm from action at which 
they would prefer the act to the omission. (The harm from the omission is held constant.) In the vaccination scenario, a few subjects say zero. That is, they would not vaccinate a group of children if the vaccine caused a single death. Many more subjects give some number between zero and 9, and some say 9 or 10. (The precise percentages vary from study to study.)

This limitation of PVs to acts is a natural concomitant of absoluteness. It results from the need to limit obligations. If people thought they were as absolutely obliged to prevent some harm as not to cause it, their absolute obligations would be multiplied. It is surely impossible to take every possible action that would prevent some sort of harm (such as the death of a person), although it may be possible to avoid all actions that would cause a harm.

The prediction that omission bias is stronger for PVs is important to Baron and Spranca's theory because it is a direct test of the central claim of the theory, which is that most PVs are prohibitions against actions. Note that we do not hypothesize a perfect correlation between PVs and omission bias, for two reasons. First, PVs are not the only source of omission bias. Omission bias can also result from loss aversion (coupled with a tendency to see omission as the reference point) and norm theory (Baron \& Ritov, 1994).

Second, as we noted earlier, people with PVs also care about consequences. If the demands of consequences are sufficiently strong, they may be willing to compromise the absoluteness of their deontological rule, while preserving its nature as a rule about action. They may thus be willing to endorse causing a certain harm to prevent much much more of the same harm. This is also the reason we do not expect the strongest form of our hypothesis to be supported. In the strongest form, all PVs would be associated with zero thresholds. People with PVs would not accept any harm at all from action, regardless of theamount of harm that it would prevent. Although we expect a correlation between PVs and zero thresholds, the weaker hypothesis says only that the deontological prohibition on action is one consideration that is weighed against other considerations, such as those based on consequences. This weaker hypothesis is consistent with the results of Baron and Leshner (1999), who found several other ways in which people qualify their commitments to PVs.

In the last experiment here, we explore another way in which people might limit the obligations that arise from PVs. PVs may be somewhat limited to trade-offs with gains, rather than losses. It is more difficult to avoid sacrificing a PV if our only alternative is to suffer a loss than if our only alternative is to forgo a gain. A distinction between losses and gains further limits the scope of protected values.

Experiments 2 and 3 also explore the relationship between PVs and the effect of quantity. If violation of a PV is absolutely wrong, then the size of the effect does not matter. It cannot get any worse. Moreover, it is the act that matters, not the size of the effect. We ask whether this insensitivity to quantity extends to the number of acts and the number of actors. The original theory makes no clear prediction here. On the one hand, two offenses might be seen as worse than one. On the other, if the wrong is all-or-none, then it is not any worse if it happens twice. 
The experiments use opinions about hypothetical cases because these are anal ogous to the materials used when researchers try to elicit value judgments for the purpose of making policy. We are not concerned here with whether people express their PVs in their behavior. Arguably, public policy should be based on what people say they want rather than on how they express their wants in their behavior (Baron, 1997). If their behavior disagrees with their true values, they may regret their behavior.

\section{EXPERIMENT 1}

Experiment 1 uses the basic paradigm of Ritov and Baron (1990), in which subjects make hypothetical choices, each between an act and an omission, with the act leading to less harm than the omission. Subjects provide a threshold amount of harm for the act, above which they would choose the omission. We used 11 cases of this type, each with a different consequence. The cases represented the variety used in previous studies of omission bias. Some were realistic, and others were not. Omission bias has been found before in both kinds of cases. After subjects responded to these items, they indicated whether they had PVs against causing each consequence.

If, as hypothesized, PVs apply to acts more than to omissions, then the action thresholds should be lower for PVs. We tested this hypothesis by computing, for each case, a correlation across subjects between threshold and PV (which is dichotomous, 1 for presence of a PV and 0 for absence). Each of these correlations is negative if those with a PV for the value represented in the case have a lower threshold than those without such a PV. That is, those with a PV are more reluctant to cause harm through action, holding constant the harm from omission. U pon finding negative correlations, we asked whether these correlations are general across the cases by asking whether their mean, across the 11 cases, is less than zero. Thus, we considered the cases as replications of the basic question about individual differences, and we tested across replications.

We also performed subsidiary analyses, especially concerning the generality of individual differences across items in PVs and in omission bias. No previous study of omission bias has found a general tendency to show omission bias, across items. Because each experiment uses several cases, we have a chance to test for such a general tendency for the first time. We ask whether the mean threshold is a reliable measure of individual differences.

\section{Method}

Subjects were 78 I sraeli students: 44 from the Hebrew U niversity of J erusalem, 34 from the University of Haifa; 42 females, 35 males (and 1 unidentified); 42 J ews, 34 Arabs (and 2 others who were excluded from analysis of nationality). The questionnaire was in Hebrew, and subjects completed it without pay.

The questionnaire began, "You are a government official and must make choices about whether or not to institute new programs. Money is not an issue; these programs are part of the normal operation of your department. But each 
program has negative effects as well as beneficial ones." A typical item (the first) read (in translation):

Starvation. A convoy of food trucks is on its way to a refugee camp during a famine in Africa. (Airplanes cannot be used.) You find that a second camp has even more refugees. If you tell the convoy to go to the second camp instead of the first, you will save 1000 people from death, but 100 people in the first camp will die as a result.

Would you send the convoy to the second camp? $\mathrm{Y} \quad \mathrm{N}$

What is the largest number of deaths in the first camp at which you would send the convoy to the second camp?

The questionnaire then asked, after each item, "How much do you care about this?" Subjects responded on a scale from 1 (not at all) to 10 (highly).

Two items ( 3 and 9 ) are omitted from analysis because they were misworded. The second item was essentially the same as the vaccination item use by Ritov and Baron (1990). The remaining items were (in summary form):

4. Government support. Your office provides financial assistance to a plant employing 50 workers. If you withdraw this support (which will put 50 workers out of work) you can use the funds to support another plant, which employs 500 workers. Without government support, this second plant will close down.

5. Medical assistance. Funds for cancer treatments for poor people are limited. Right now, the program you run covers an expensive treatment that cures 100 people each year. If you stop covering this treatment completely, you can use the same money for another, less expensive, treatment that can cure 1000 people of an equally bad kind of cancer....

6. Civil rights. A prosecutor who works for you has just begun to work on a case involving discrimination against a minority in applications for mortgages. Ten instances of discrimination are involved. A similar case comes to your attention, and you have have no other prosecutor to assign. The new case involves 100 instances of discrimination....

7. Combating traffic accidents. A program to combat accidents saves 50 lives per year in a specific area. The same funds could be used to save 200 lives in another area, but the 50 lives in the first area would be lost.

8. Settlement. You are a member of a committee in a new J ewish settlement. If you agree to leave, the government intends to give the area of your settlement back to the Palestinian (an area of 50 units). The government proposed that you move to a new settlement. This settlement will include an area of 500 units. If you don't move, this second area will be turned over to the Palestinians.

10. I krit and Bir'am (two Arab villages evacuated in 1949). The government is now willing to return $40 \%$ of the area to the Arab original residents, in return for an agreement to withdraw further claims and public campaigns. You are one of the leaders of the campaign. (The subject was then asked about "the largest percent remaining a military area that you would be willing to accept in return for an agreement to stop the campaign.")

11. Nature preserves. An area of 200 units of a nature preserve is currently used by the army. It is willing to exchange it for another area, of 50 units, which is also a nature preserve. 
12. Shelters for battered women. A budget used to finance a shelter holding 50 women in the center can be used, instead, to establish three shelters in the peripheral areas, with a total of 150 places.

13. Sabbath observance. You are a nonreligious resident of a town with a minority of religious J ews. The current status quo allows opening businesses and recreational facilities on the Sabbath, in an area including four streets. The religious minority is interested in closing down this area on the Sabbath, and is willing, in exchange, to allow for opening of businesses in another recreational area including 20 streets.

After these items, subjects chose one response to questions designed to measure whether the subject had a PV for the case. Each question was of the following form:

Letting people die from starvation. I do not object to this.

This is acceptable if it leads to some sort of benefits (money or something else) that are great enough.

This is not acceptable no matter how great the benefits.

The subject chose one answer. If the subject chose the third (not acceptable), the subject was counted as having a PV for the value at issue. Cases with the first answer (do not object) were eliminated for analysis of PVs and omission thresholds. (Although this answer makes no sense for starvation, it makes sense for some other items.)

Finally, subjects were asked a number of demographic questions, including sex, nationality, and degree of religious commitment.

\section{Results}

For most of the values, subjects with protected values had lower thresholds for omission, as hypothesized. In addition, subjects showed consistent individual differences in their threshold responses and in their PV responses. Degree of caring did not account for the correlation between PVs and thresholds.

F orty-three percent of the values were protected. To measure omission bias, we converted each threshold to a proportion, by dividing the threshold response by the number that would suffer harm from omission. Thus, for example, if the largest number of deaths in the first camp at which the subject would send the convoy to the second camp was 400 , the threshold ratio would be .4 , since 1000 people would die if no action were taken. The threshold ratios varied from 0 (unwilling to accept any harm from action) to 1 . (The few responses greater than 1-less than 1\%-were assumed to be errors and were reduced to 1.) The mean threshold ratio for action was .33.

Twelve percent of the thresholds were zero, that is, the subject was unwilling to accept any harm from action. This is substantially lower than the $43 \%$ rate for PVs. The strong form of the hypothesis, which implies that all PVs are associated with zero thresholds, can be rejected.

Mean caring response was 8.0 (on a scale of 10). Reliabilities $(\alpha)$ for these measures were .83 for PVs, .74 for thresholds, .60 for zero thresholds, and .78 
for caring. These reliabilities support the generality of individual differences in PVs and thresholds. This has not been reported before.

To test the main hypothesis, we computed the correlation, across subjects between threshold and PV ( 1 or 0 ) for each of the eight cases. The mean of these correlations, across the eight cases, was -.34 ( $\left.\mathrm{t}_{10}=10.35, \mathrm{p}<.0005\right)$. The mean threshold was .20 for items with PVs and .43 for items without PVs. Thus, subjects with PVs tended to have lower thresholds. Table 1 shows the mean thresholds by item, as well as proportion of zero responses, mean caring response, and proportion of PVs.

Greater caring also correlated with PVs (mean $r=.16, t_{10}=3.66, p=.004$, across the 11 items), and with lower thresholds (mean $r=-.16$ with the threshold, $\mathrm{t}_{10}=4.29, \mathrm{p}=.002$ ). We can ask whether the correlations of both PVs and threshold with caring mediate the correlation between PVs and threshold. This hypothesis is inconsistent with the fact that the correlation between thresholds and PVs was consistently greater, across items, than that between thresholds and caring ( $\left.\mathrm{t}_{10}=4.20, \mathrm{p}=.002\right)$. If caring accounted for the correlation, then thresholds would correlate at least as highly with caring as with PVs. (Baron and Treiman, 1980, discuss why comparison of correlations is superior to partialling when, in cases like the present case, the hypothesized mediator is not measured with perfect validity. In this case, partialling does not remove all the variance of the hypothesized mediator, and a significant partial correlation is consistent with complete mediation. Baron and Treiman also pointed out that the inference from comparison of correlations requires ruling out differential reliability of the measures as an alternative explanation. As we noted, the reliability of caring is nearly as high as that of PVs-.78 vs .83-so this alternative explanation is unlikely to be true.)

PVs were also associated with zero thresholds, which represent complete unwillingness to act in a way that causes the harm in question. The mean

TABLE 1
Mean Threshold Ratios, Proportion of Zero Thresholds, Mean Caring Ratings According to Presence or Absence of PV, and Proportion of PVs for the Cases Used, Experiment

\begin{tabular}{|c|c|c|c|c|c|c|c|}
\hline \multirow[b]{2}{*}{ Item } & \multicolumn{2}{|c|}{ Threshold } & \multicolumn{2}{|c|}{ Zeros } & \multicolumn{2}{|c|}{ Caring } & \multirow[b]{2}{*}{ Proportion PV } \\
\hline & PV & no-PV & PV & no-PV & PV & no-PV & \\
\hline 1. Starvation & .30 & .50 & .12 & .00 & 8.2 & 8.0 & .63 \\
\hline 2. Vaccination & .09 & .37 & .43 & .02 & 8.6 & 8.7 & .39 \\
\hline 4. Government support & .14 & .36 & .08 & .03 & 9.0 & 7.4 & .18 \\
\hline 5. Medical assistance & .21 & .49 & .17 & .04 & 8.8 & 8.9 & .63 \\
\hline 6. Civil rights & .21 & .43 & .20 & .06 & 8.0 & 6.9 & .54 \\
\hline 7. Accidents & .44 & .54 & .07 & .03 & 8.8 & 8.8 & .58 \\
\hline 8. Settlement & .03 & .32 & .56 & .10 & 9.4 & 7.9 & .23 \\
\hline 10. I krit \& Bir’am & .08 & .27 & .48 & .09 & 9.2 & 7.6 & .38 \\
\hline 11. Nature preserves & .27 & .46 & .29 & .01 & 7.9 & 7.3 & .30 \\
\hline 12. Battered women & .28 & .53 & .22 & .08 & 9.2 & 8.0 & .32 \\
\hline 13. Sabbath & .12 & .46 & .52 & .00 & 7.8 & 7.3 & .37 \\
\hline
\end{tabular}


proportion of zero thresholds was .28 for PV and .04 for non-PV items. As we noted, the .28 is much lower than the 1.00 predicted by the strong form of our hypothesis. The weak form of our hypothesis predicts a correlation between PVs and zero thresholds, however: some PVs will be taken as absolute, to be honored regardless of the consequences. To test this correlation, we computed $\gamma$ (a measure of association from Goodman \& Kruskal, 1954: [the number of pairs of subjects in which one had both a PV and a zero and the other had neither minus the number in which one had a PV and the other had a zero]/ [the sum of these numbers]) between zero thresholds and PVs for each item. The mean $\gamma$ was .73, which was significantly greater than zero across items $\left(\mathrm{t}_{10}=10.79, \mathrm{p}<.0005\right)$.

Our tests so far were based on treating the 11 cases as replications of an experiment on individual differences; we computed the correlation of interest for each case and then tested across the cases. We can also test general individual differences by computing for each statistic of interest the mean for each subject, across the 11 cases, and then testing the correlations of these means across subjects. For example, the mean PV measure was simply the proportion of PVs that the subject endorsed. The important correlations were replicated when tested in this way: $r=-.39$ for PVs and threshold $(p<.001)$, and $r=.43$ for PVs and zero responses $(p<.0005)$. Correlations between caring and PVs and between caring and threshold were not significant.

Although omission bias was greater for PVs, it remained for non-PVs. We counted a threshold response as showing omission bias when it was less than 1 less than equality between effects of action and omission (e.g., less than 499 for item 4). By this criterion, $86 \%$ of non-PV thresholds showed omission bias, with a minimum (across the 11 items) of .77.

In general, demographic measures were unrelated to measures of omission bias or PVs, and regressions of omission bias and PVs on all the variables together were not significant.

\section{EXPERIMENT 2}

Experiment 2 replicates Experiment 1 with additional questions comparing one and two acts, with somewhat different items, and without the questions about caring.

Baron and Spranca (1997) found that sensitivity to the quantity of the outcome was reduced when PVs were present. If PVs concern actions rather than consequences, perhaps PVs are sensitive to the quantity (number) of actions rather than to the quantity of consequences. People with PVs could think that it is worse to violate them twice than once, even if the consequences of the two violations are the same as those of the one. The question here is whether PVs are associated with insensitivity to quantity of any sort or whether they are simply insensitive to quantity of the consequences.

The effect of number of actions need not be limited to PVs. Previous research suggests that two bad outcomes are considered worse than a singlebad outcome, keeping total badness of the outcomes constant (Ritov, Baron, \& Hershey, 
1993; Thaler, 1985). The outcome of two bad acts may be regarded as two bad outcomes.

On the other hand, quantity insensitivity could be more general, extending to number of actions. This possibility is suggested by an association of PVs with character judgments resulting from immoral acts (Sabini Silver, 1982, Chap. 8). We call someone a liar or a murderer as a result of a single act; the stain of such violations is permanent and not dependent on the number of acts committed.

\section{Method}

Thirty-seven subjects-mostly students at the University of Pennsylvania and the Philadel phia College of Pharmacy and Science-completed a questionnaire on "decision conflicts." They were paid $\$ 6 /$ hour for completing this questionnaireand others. One subject had more than half of thethreshold responses inconsistent with theyes-no responses and was el iminated, leaving 36 subjects (15 males). Another subject did not answer the threshold questions, leaving 35 for analyses involving these questions. Seventeen of the subjects completed the questionnaire on the World Wide Web for a flat fee. Almost all subjects were university students (most from the United States).

The questionnaire was like that used in Experiment 1, except that the PV items replace the "I do not object" option (which was rarely chosen) with "This is acceptable if it saves people enough money," thus providing two alternatives to the PV response of "This is not acceptable no matter how great the benefits." The other alternative was still "This is acceptable if it leads to some sort of benefits (money or something el se) that are great enough." Subjects could check more than one option, but no subject checked the PV option and one of the other two.

Items 1, 3, 5, and 6 were the same as Items 2, 1, 6, and 5, respectively, in Experiment 1. The remaining items were as follows (in abbreviated form):

2. River diversion. As a result of a dam on a river, 20 species of fish are threatened with extinction. By opening the dam for a month each year, you can save these species, but 2 species downstream will become extinct because of the changing water level.

4. Cutting forests. A logging company has the rights to 1000 square miles of old-growth forest. The company is willing to trade this land for 100 square miles of similar land, now part of a national park. You can give the smaller area to the company and make the larger area into a national park.... The logging company will cut all the trees in whichever area it owns.

7. Child labor. You are a buyer for a large clothing chain. You are buying clothes from supplier A in a poor country, who employs 1000 ten-year-old children to work at sewing machines. You can switch to supplier B. You know that B will start factories that will employ 100 ten-year-olds who are now not working. ...

8. Dolphins. You are in charge of regulating some tuna fishing boats. The boats now fish in an area in which they catch 1000 dolphins per year. The 
dol phins die in the nets, unable to breathe. You could require the boats to move to another area, where they would catch just as many tuna, but 100 dol phins instead of 1000.

In addition-to test for an effect of number of actions-after each threshold question, we asked an additional question of the following form (again, shown for the second question):

Which is worse? (Choose one.)

i. An official opens a dam to save money on repairs, and, as a result, two different species of fish become extinct.

ii. An official opens two dams to save money on repairs, and one species of fish becomes extinct as a result of opening each dam (for a total of two species).

iii. These are equally bad.

iv. These are not necessarily bad at all.

\section{Results}

The main results of Experiment 1 were replicated, and PVs were associated with thinking that two acts are no worse than one, supporting the general quantity-insensitivity hypothesis, but only weakly.

We omitted items if the yes-no question disagreed with the numerical answer: one subject was omitted because this happened more than half the time; it happened $5 \%$ of the time for the remaining subjects. The mean threshold for action was .49 (reliability coefficient $\alpha=.85$ ), the mean proportion of zero thresholds was $.04(\alpha=.50)$, and the mean proportion of PVs was .53 $(\alpha=.86)$. Themean correlation between threshold and PVs, computed across subjects and then averaged across the eight cases, was $.29\left(\mathrm{t}_{7}=3.90, \mathrm{p}=.006\right)$. (The mean threshold was .38 for PV items, .60 for no-PV items.) The mean $\gamma$ between zero thresholds and PVs was .68 $\left(\mathrm{t}_{6}=2.40, \mathrm{p}=.053-\right.$ variability was high because of the small number of zero thresholds). In addition, we found an overall correlation across subjects between the proportion of PVs and the mean threshold ( $r=-.47, p=.004)$, but no other across-subject correlations of these variables were significant. Although men had higher thresholds (mean difference $.20, t=2.40, p=.022$ ), the overall effect of sex on the main dependent measures was not significant, and this effect was not found in Experiment 1. There was no effect of Web vs lab subjects on any measure.

As in Experiment 1, omission bias was not restricted to PVs, but was still found in $79 \%$ of the non-PV cases (averaged across items), with the minimum item 58.

Subjects more often considered two acts to be worse (13.2\%) than one act (3.6\%; $t=3.40,=p=.002$ for the difference across subjects). To determine whether this distinction was related to PVs, we needed to measure it for each response. To do this, we formed a binary variable that distinguished "two acts worse" from "equally bad," for each response, eliminating responses with one act worse or neither act bad. Weexamined the association between this variable and PV for each item. The mean $\gamma$ across subjects was $-.32\left(t_{7}=2.40 ; p=\right.$ .048 , two-tailed). PVs are associated with the judgment that one act and two 
acts are equally bad. Possibly, PVs are associated with a judgment of overall character, but, for non-PVs, subjects are consistent with previous findings that two bad things are worse than one. Clearly, the hypothesis that PVs are more sensitive to the number of actions is incorrect.

\section{EXPERIMENT 3}

Perhaps people with PVs are sensitive to the number of actors, if not to the number of actions. In Experiment 2, the number of actors was ambiguous in many cases. In Experiment 3, we explicitly distinguished the number of actions and actors.

\section{Method}

Seventy-three subjects (33 on the Web, 40 in the lab; 41 females, 32 males) completed a questionnaire. The PV question, again given last, was the same as in Experiment 2. The questionnaire had no threshold question. The action question was of the following form:

A. An official opens a dam to save money on repairs, and, as a result, two different species of fish become extinct.

B. An official opens two dams to save money on repairs, and one species of fish becomes extinct as a result of opening each dam (for a total of two species).

C. Two officials open different dams to save money on repairs, and one species of fish becomes extinct as a result of opening each dam (for a total of two species).

Check all that apply:

$-\mathrm{B}$ is worse than $\mathrm{A}$.
$\mathrm{C}$ is worse than $\mathrm{B}$.
$\mathrm{C}$ is worse than $\mathrm{A}$.
$\mathrm{B}$ is no worse than $\mathrm{A}$.
$\mathrm{C}$ is no worse than $\mathrm{B}$.
$\mathrm{C}$ is no worse than $\mathrm{A}$.
$\mathrm{A}, \mathrm{B}$, and $\mathrm{C}$ are not bad at all.

We counted only the checks to the first three options (since many subjects neglected to fill in all of the necessary "no worse" options when they did not check all of the first three). In three cases, we inferred " $C$ is worse than A" from checks on the first two only. We omitted cases in which the subject said "not bad at all" (4.8\%). The eight items were based on those of Experiment 2.

\section{Results}

Again, PVs were weakly associated with insensitivity to number of acts, but they were not associated at all with sensitivity to number of actors.

Subjects were sensitive to number of acts (B worse than $A$ ) in $31 \%$ of the cases $(\alpha=.88)$, to number of actors (C worse than B) in 27\% $(\alpha=.90)$, and to both ( $\mathrm{C}$ worse than $\mathrm{A}$ ) in $33 \%(\alpha=.89)$. Subjects had PVs (after removing "not bad at all") in $77 \%$ of the cases $(\alpha=.65)$.

The mean $\gamma$, across the eight cases, between sensitivity to acts (B worse than 
A) and PVs was -.21 ( $t_{7}=2.14 ; p=.070$, two-tailed). No other associations with PVs approached significance (mean $\gamma^{\prime}$ 's were - .14 for both $C$ worse than $B$ and $C$ worse than $A$ ). However, judgments of acts and actors were highly correlated: mean $\gamma$ between $C$ worse than B (sensitivity to number of actors) and $B$ worsethan $A$ (sensitivity to number of acts) was .72 ( $t_{7}=23.39, p<.0005$ ).

The results of this study provide further evidence against the hypothesis that PVs are associated with any sort of sensitivity to quantity, whether of the number of acts or of the number of actors. The sensitivity to number of acts in non-PV items is, again, consistent with previous findings. And the lack of association between PVs and number of actors is consistent with the hypothesis that insensitivity to number of acts for PVs is associated with a judgment of moral character of the actor.

\section{EXPERIMENT 4}

Experiment 4 replicated the main result, the correlation between PVs and omission bias. It also asked whether PVs are found for losses as well as gains. The critical questions in earlier studies concerned whether each value should be sacrificed in order to obtain some benefit. Here, we also ask whether each value should be sacrificed to prevent a loss. J ust as limiting PVs to actions places a limit on the obligation to maintain them, so does limiting them to gains rather than losses. Of course, this would make the status quo special with respect to PVs. The values would be protected from sacrifice for gains only, relative to the status quo.

In this experiment, we also ask more than one question about protected values. Conceivably, having a PV is a continuum rather than a dichotomy; or, alternatively, it could be a dichotomy but with error in its expression (because of momentary inattention or misunderstanding, for example).

\section{Method}

Ninety-eight subjects completed a questionnaire on the Web. (Three others completed it but were eliminated because more than half of their answers to threshold questions were inconsistent with their yes-no answers.) They were $68 \%$ female, and $43 \%$ students, and they ranged in age from 17 to 50 (median 25).

The cases were the same as Experiment 2 (with minor editing), plus the following:

9. Voting. You are voting in a country in which the legislature is elected by party slates of about 40 each. Each party is represented according to the number of votes it gets. In party $\mathrm{R}, 20$ of the candidates in the slate have made openly racist comments during the campaign. In party S, 2 of the candidates have made racist comments. Except for this issue, you regard $\mathrm{R}$ and $\mathrm{S}$ as equally good. You would prefer party $\mathrm{T}$, but you feel that $\mathrm{T}$ has little chance for any representation, and the only way you can stop $\mathrm{R}$ is by voting for $\mathrm{S}$.

Would you vote for S?

What is the largest number of candidates making racist comments in party $\mathrm{S}$ at which you would vote for $\mathrm{S}$ ? 
The measure of omission bias was based on the answer to the last question as a proportion of the higher amount (here 20), with proportions greater than 1 lowered to 1 . We call this the threshold for action. We eliminated items if theyes-no question disagreed with the threshold question. (The three subjects eliminated had more than half disagreements.)

At the end of the questionnaire, the following questions were asked about each action. For each item, the subjects indicated which statements they agreed with and which they disagreed with. The number in parentheses after each item is the mean score on that item, which can range from 1, for agreement, to -1 , for disagreement.

A. This is acceptable if it leads to economic benefits that are great enough. $(-.40)$

B. This should not be allowed for the sake of economic gains, no matter how great the gains. (.25)

C. This is acceptable if it prevents economic losses that are great enough. (-.35)

D. This should not be allowed for sake of preventing economic losses, no matter how great the losses. (.11)

E. This is acceptable if it prevents more of the same thing. (.30)

F. This should never be allowed, even if it prevents more of the same thing. (-.42)

G. This is unacceptable as a general rule, but we should allow it sometimes if it prevents very great economic losses. (-.19)

$\mathrm{H}$. This is unacceptable as a general rule, but we should allow it sometimes if it leads to very great economic benefits. (-.31)

Questions $\mathrm{G}$ and $\mathrm{H}$ are not analyzed. They were included to allow subjects to express strong opposition without committing themselves to absolute opposition.

We defined various indices based on the answers to these questions. To form these indices, we counted agreement with each question as 1 , disagreement as -1 , and neither agreement nor disagreement as 0 . Our indices were as follows:

$\begin{array}{ll}\text { PV } & B-A+D-C+F-E \\ \text { PVgain } & B-A \\ \text { PVloss } & D-C \\ \text { PVomission } & F-E\end{array}$

The PV index is the sum of PVgain, PVIoss, and PVomission. PVgain concerns sacrifice of a value in order to achieve gains. PVloss concerns preventing losses. PVomission essentially asks subjects whether they would sacrifice the value through action in order to prevent more of the same harm through omission. This question thus asks the same thing as the threshol d question, in a different way. The PV index ranged from 6 to -6 , and the other indices ranged from 2 to -2 . Each index was computed for each item.

\section{Results}

The main results of Experiments 1 and 2 were replicated, and PVs were stronger for gains than for losses, as hypothesized, although the difference between PVs in gains and in losses was small.

The mean threshold for action was .42 (reliability coefficient $\alpha=.88$ ). The 
mean proportion of zero thresholds was .10 ( $\alpha=.68$ ). PVs were assessed by the point system defined above. The mean PV was .39, on the scale of 6 to -6 (SD $=2.74, \alpha=.88$ ). The mean correlation between threshold and PVs, computed across subjects for each case and then averaged across the nine cases, was $-.15\left(\mathrm{t}_{8}=5.38, \mathrm{p}=.0007\right)$. The mean $\gamma$ between zero thresholds and PVs was .26 $(t=4.61, p=.0017)$. Theseresults replicatethemain results concerning correlations between PVs and omission bias.

The sample was larger than in previous experiments, and individual differences were found as a function of demographic indices. Thresholds were higher in younger subjects $(r=-.22$ with age, $p=.0288)$, males $(r=.22, p=.0318)$, and students ( $r=.21, p=.0422$; students were younger, and neither age nor student status was significant in a multiple regression). No correlation of these demographic variables with PVs was significant.

As we described earlier, we defined three different measures of PVs for each response: PV gain for gains, PVIoss for losses, and PVomission. The means of these measures were .65 for PVgain, .46 for PVloss, and -.72 for PVomission (all on a range from 2 to -2 ).

The mean difference between PVgain and PVIoss was significant across subjects $\left(t_{97}=3.11, p=.0025\right)$ and across the nine cases $\left(t_{8}=8.06, p=.0000\right)$. This supports the hypothesis that PVs are more frequent for gains than for losses. People are more willing to sacrifice a value to prevent a loss than to obtain a gain. However, this difference was small: $37 \%$ of the subjects had a mean effect of zero, making no distinction between losses and gains; $22 \%$ had greater PVs for losses; and $41 \%$ had greater PVs for gains.

PVomission was less often endorsed than PVgain or PVIoss (mean of -.72 for PVomission, different from the other two at $p=.0000$ ). In other words, people are more willing to sacrifice a value in order to prevent a greater harm to the same value than they are willing to sacrifice the value for the sake of preventing some unnamed loss or achieving a gain.

PVomission correlated more strongly with threshold than did PVgain or PVIoss. The mean correlations with threshold (across subjects for each item and then averaged over cases) were -.06 for PVgain and PVIoss and -.23 for PVomission. The PVomission correlation was lower (stronger in the predicted direction) than the other two, computed for each item and then tested across cases $\left(t_{8}=3.75\right.$ for the smaller effect, $\left.p=.0056\right)$. When subjects are given the option of expressing PVs only for "preventing more of the same thing," they do so less often than for other PVs, but this is a stronger correlate of omission bias. This result corroborates the measures we used and also suggests that PVs and omission bias have somewhat distinct determinants. They are not simply the same thing.

\section{DISCUSSION}

On the basis of the proposal that PVs result from rules concerning action, we hypothesized a correlation between PVs and omission bias. We found this correlation in three experiments, using stimuli of the sort that we used before 
to demonstrate omission bias, in which an act causes harm but prevents greater harm of the same sort. In two experiments, we also found a weak tendency for PVs to be associated with lack of concern for the number of acts involved, which is analogous to earlier results (Baron \& Spranca, 1997; Lim \& Baron, 1997) showing an association with lack of concern for the quantity of outcomes. These results together support the proposal that PVs concern actions rather than outcomes alone.

We examined the effect of number of actions and actors. Baron and Spranca (1997) found that people with PVs tended to think that the magnitude of the outcome-the number of instances affected-did not matter. This result is consistent with the proposal that PVs are about actions rather than outcomes. We might, then, expect that people with PVs would be more sensitive to the number of actions, holding constant the magnitude of the outcome. We would expect such a result if people viewed actions themselves as consequences that could be counted up in a utilitarian calculus. We would be able to treat actions as just one bad consequence to be avoided, among others. The disappearance of a species is one bad outcome, and the commission of an action that causes a species to disappear is another. Clearly, we did not find this result. We found small effects in the opposite direction. People with PVs are more likely to think that the number of actions does not matter than are people without PVs. Evidently, the opposition to actions that arises from PVs is not a utilitarian value at all. It cannot be included in a utilitarian calculation.

We also found consistent individual differences across cases in both PVs and omission bias. In the last experiment (the one with the largest sample and the highest proportion of nonstudent subjects), omission bias was greater in older subjects. The cultural and educational differences in omission bias and protected values remain to beexplored (but seeBaron, Granato, Spranca, \& Teubal, 1993, and Lim \& Baron, 1997).

The last experiment suggested that another distinction relevant to PVs is that between gains and losses relative to the status quo. As shown by Baron and Ritov (1994), this distinction is not the same as that between acts and omission. Many protected values are relevant only when a sacrifice of some value for gains is at issue. Sacrifice to avoid losses-whether by act or by omission-may beacceptable. This distinction may hel p people limit the obligations imposed by PVs. It is not a large effect, however; few subjects found it to be relevant. The gain-loss distinction is easily manipulated by framing, so the invocation of protected values, in such subjects, may be affected by how an issue is presented.

\section{REFERENCES}

Arkes, H. R., Dawes, R. M., \& Christensen, C. (1986). Factors influencing the use of a decision rule in a probabilistic task. Organizational Behavior and Human Decision Processes, 37, 93- 110.

Asch, D., Baron, J ., Hershey, J . C., Kunreuther, H., Meszaros, J ., Ritov, I., \& Spranca, M. (1994).

Determinants of resistance to pertussis vaccination. Medical Decision Making, 14, 118- 123.

Baron, J . (1992). The effect of normative beliefs on anticipated emotions. J ournal of Personality and Social Psychology, 63, 320-330. 
Baron, J . (1997). Biases in the quantitative measurement of values for public decisions. Psychol ogical Bulletin, 122, 72-88.

Baron, J ., Granato, L., Spranca, M., \& Teubal, E. (1993). Decision making biases in children and early adolescents: Exploratory studies. Merrill Palmer Quarterly, 39, 23-47.

Baron, J ., \& Leshner, S. (1999). How serious are protected values? Manuscript, Department of Psychology, University of Pennsylvania.

Baron, J ., \& Ritov, I. (1993). Intuitions about penalties and compensation in the context of tort law. J ournal of Risk and Uncertainty, 7, 17-33.

Baron, J ., \& Ritov, I. (1994). Reference points and omission bias. Organizational Behavior and Human Decision Processes, 59, 475- 498.

Baron, J ., \& Spranca, M. (1997). Protected values. Organizational Behavior and Human Decision Processes, 70, 1- 16.

Baron, J ., \& Treiman, R. (1980). Some problems in the study of differences in cognitive processes. Memory and Cognition, 8, 313-321.

Cohen, B. J ., \& Pauker, S. G. (1994). How do physicians weigh iatrogenic complications? J ournal of General Internal Medicine, 9, 20-23.

Goodman, L. A., \& Kruskal, W. H. (1954). Measures of association for cross-classifications. J ournal of the American Statistical Association, 49, 732-764.

Lim, C. S., \& Baron, J . (1997). Protected values in Malaysia, Singapore, and the United States. Manuscript, Department of Psychology, University of Pennyslvania.

Meszaros, J . R., Asch, D. A., Baron, J ., Hershey, J . C., Kunreuther, H., \& Schwartz-Buzaglo, J . (1996). Cognitive processes and the decisions of some parents to forego pertussis vaccination for their children. J ournal of Clinical Epidemiology, 49, 697-703.

Petrinovich, L., \& O'Neill, P. (1996). Influence of wording and framing effects on moral intuitions. Ethology and Sociobiology, 17, 145-171.

Ritov, I., Baron, J . (1990). Reluctance to vaccinate: Omission bias and ambiguity. J ournal of Behavioral Decision Making, 3, 263-277.

Ritov, I., \& Baron, J . (1992). Status-quo and omission bias. J ournal of Risk and Uncertainty, 5, 49-61.

Ritov, I., \& Baron, J . (1995). Outcomeknowledge, regret, and omission bias. Organizational Behavior and Human Decision Processes, 64, 119-127.

Ritov, I., Baron, J ., \& Hershey, J . C. (1993). Framing effects in the evaluation of multiple risk reduction. J ournal of Risk and Uncertainty, 6, 145-159.

Sabini, J ., \& Silver, M. (1982). Moralities of everyday life New York: Oxford Univ. Press.

Spranca, M., Minsk, E., \& Baron, J. (1991). Omission and commission in judgment and choice. J ournal of Experimental Social Psychology, 27, 76-105.

Steiger, J . H. (1980). Tests for comparing elements of a correlation matrix. Psychological Bulletin, 87, 245-251.

Thaler, R. (1985). Mental accounting and consumer choice. Marketing Science, 4, 199-214.

Received J uly 29, 1998 